\title{
Predicting the Safety Climate in Construction Sites of Saudi Arabia: A Bootstrapped Multiple Ordinal Logistic Regression Modeling Approach
}

\author{
Anas A. Makki ${ }^{1, *(1)}$ and Ibrahim Mosly ${ }^{2}(\mathbb{D}$ \\ 1 Department of Industrial Engineering, Faculty of Engineering—Rabigh Branch, King Abdulaziz University, \\ Jeddah 21589, Saudi Arabia \\ 2 Department of Civil Engineering, Faculty of Engineering-Rabigh Branch, King Abdulaziz University, \\ Jeddah 21589, Saudi Arabia; ikmosly@kau.edu.sa \\ * Correspondence: nhmakki@kau.edu.sa
}

Citation: Makki, A.A.; Mosly, I. Predicting the Safety Climate in Construction Sites of Saudi Arabia: A Bootstrapped Multiple Ordinal Logistic Regression Modeling Approach. Appl. Sci. 2021, 11, 1474 https://doi.org/10.3390/app11041474

Academic Editor: Chiara Bedon

Received: 28 December 2020

Accepted: 3 February 2021

Published: 6 February 2021

Publisher's Note: MDPI stays neutral with regard to jurisdictional claims in published maps and institutional affiliations.

Copyright: (c) 2021 by the authors. Licensee MDPI, Basel, Switzerland. This article is an open access article distributed under the terms and conditions of the Creative Commons Attribution (CC BY) license (https:// creativecommons.org/licenses/by/ $4.0 /)$.

\begin{abstract}
Construction site accidents can be reduced through proactive steps using prediction models developed based on factors that influence the safety climate. In this study, a prediction model of the safety climate observed by construction site personnel in Saudi Arabia was developed, identifying a set of significant safety climate predictors. The model was built with data collected from 401 active construction site personnel using a bootstrapped multiple ordinal logistic regression model. The model revealed five significant predictors: supervision, guidance, and inspection; social security and health insurance; management's commitment to safety; management's safety justice; and coworker influence. The model can correctly predict $67 \%$ of the safety evaluations. The identified predictors present proof of the importance of safety support, commitment, and interaction in construction sites and their influence on the perceived evaluations of the safety climate by personnel. Moreover, the prediction model can help construction industry decision makers, safety policy designers, government agencies, and stakeholders to estimate the safety climate and assess the current situation. Furthermore, the model can help form a better understanding and determine areas of improvement, which can translate into higher safety performance levels.
\end{abstract}

Keywords: safety climate; construction sites; prediction; ordinal logistic regression; Saudi Arabia

\section{Introduction}

Many occupational accidents in construction projects are triggered by human error, inadequate supervision, and the shortage of safety facilities and equipment [1]. Most of these accidents are related to the construction industry's work environment. Managing construction projects presents several challenges related to the changing work environment and the complicated interaction between factors that affect safety [2]. The dynamic nature of the construction industry and its risks requires dynamic solutions. Naturally, the safety climate is dynamic and represents an organization's safety culture, reflecting the employees' perception and approach toward the current safety systems implemented in construction projects [3]. The impact and influence of the safety climate on safety performance are well recognized [4-8]. To accomplish high safety performance levels in construction projects, several connected factors should be considered, including key safety management factors, contextual factors, and a combination of such factors [9]. Safety management factors, including roles and responsibilities, project management, occupational health and safety (OHS) management and integration, safety climate, learning, site management, staff management, and operative risk management, were identified as essential for high safety performance [9]. A study that took place in Morocco's construction industry, which endures low safety performance, found that a positive safety climate appears to counteract the negative effect that high-risk tolerance imposes on safety behavior [10]. Ethnic minority 
construction workers are vulnerable to accidents, which emphasizes the importance of determining potential strategies to improve construction sites' safety climate that will lead to improved safety performance [11]. Moreover, the safety climate can assist industry owners and contractors by providing information related to attitudes and perceptions, which can promote enhanced safety performance [12]. Furthermore, the safety climate has a major impact on safety compliance and participation $[13,14]$. There is an assumed correlation between the safety climate and safe work behavior [15], as workplace accidents are related to unsafe behaviors [16]. Construction sites' top management, such as project managers, are key players in determining site safety. Project managers must implement the corrective actions required to decrease the probability of accidents that result from workers' unsafe work behavior [17].

Several studies have investigated the safety climate in the construction industry from a different perspective. A number of these studies resulted in the creation of tools, models, and frameworks that can enhance the safety climate in the construction industry. For instance, a study proposed and tested a theoretical cognition framework incorporating construction workers' safety perception in a step toward contributing to the knowledge in the field of safety culture and safety climate [18]. It found that more experienced workers have more reliable perceptions [18]. Moreover, a study that integrated signaling theory with safety climate found that managers who perceived safety climate and workers who are committed to safety interrelate to form an effective workplace safety system [19]. In addition, a study that took place in Denmark found that an intervention with a checklist approach can assist in improving the safety climate in small construction companies where apprentices receive their training [20], thus preventing apprentice injuries as they are subjected to increased risk of occupational injuries [20]. Furthermore, the safety climate is considered to be the most effective safety factor for workers' unsafe behaviors according to a study that used a scoring matrix that is based on an interval-valued, intuitionistic, fuzzyimproved score function and a weighted divergence-based approximation approach [21]. Additionally, the safety climate assessment tool allows companies to use rubric-based descriptors for self-assessment of their safety climate maturity in a reliable manner [22]. Finally, a study was able to calculate the optimal percentage that construction companies should invest and allocate for safety equipment and activities, which was identified to be $1 \%$ of the project scope [23].

The safety climate perceptions of managers, supervisors, and workers were also investigated by a group of researchers due to their differences. It was found that the highest safety climate scores were achieved by managers, followed by supervisors and workers [24]. A study concluded that when a change in the supervisor safety climate was done from low to higher levels, the effect of risk perception on safety motivation altered from positive to negative [25]. Furthermore, workers who were working in their positive coworkers' safety climate changed their negative effect of risk perception into a positive effect concerning motivation and behavior [25]. Another study concluded that for supervisors, the safety climate is negatively correlated with injuries, whereas for workers, the safety climate is negatively associated with unsafe events [26]. In addition, a study observed that workers with a positive safety climate show higher levels of hazard realization and safety risk perception [27]. Furthermore, it was found that construction workers' risk-taking behavior is negatively correlated with the safety climate [28].

The relationship between the safety climate and safety training programs was also explored. For example, in Hong Kong and China, it was found that safety programs can improve construction workers' prosociality and the safety climate [29]. Generally, safety management programs are used in construction projects to avoid workplace injuries and provide a safety climate [30]. In addition, the safety climate can be strengthened at construction sites through specific training programs, such as the 2.5-h Foundation for Safety Leadership, given to supervisors [31]. Furthermore, a foundational safety leadership training program can assist the majority of construction companies in empowering their leaders to be able to create a sound construction site safety climate [32]. Leadership skills 
are required to establish a sound job site safety climate, which is a skill some construction foreman may lack. Specialized safety training could be used to develop the skills of personnel in the area of leadership to promote a safety climate. The foundation for the safety leadership training module is a useful approach that could assist in solving this issue, as it has been widely recognized by the construction industry [33].

Generally, communication influences safety in the construction industry. A study that used information and communication technology to investigate the relationship between safety and quality has found that this technology could lead to a 30\% improvement in quality and a $90 \%$ reduction in unsafe activities [34]. The safety climate can have a major impact on the safety outcome of a project if team members practice effective communication with each other [35]. Moreover, hazard recognition skills can be experienced by maintaining a positive safety climate. Furthermore, hazard recognition skills are also positively associated with social network safety communication patterns [36].

To achieve exceptional safety performance, it is essential to implement proactive safety management and identify a project's risk level before it begins [37]. This prediction process should include all types of risks and hazards, including those that might happen to workers. The emerging field of construction safety prediction allows predicting the likelihood and severity of future injuries by using data and analytical techniques [38]. For the past 30 years, safety literature has concentrated on the safety climate's role in predicting injuries and accidents [39]. Past studies have confirmed that the safety climate is a strong predictor of safety-related results [40], emphasizing the safety climate's importance in raising safety performance through prediction techniques. Accident prediction can help managers apply protective actions by identifying hazards early [41]. Although avoiding safety accidents is significant for construction safety, limited studies have created a system framework or model that enables construction safety experts to perform decisions before beginning work [42]. Thus, this area of research deserves more focus.

Machine learning can be used to predict safety outcomes in the construction industry. For instance, one study used two machine learning models, random forest and stochastic gradient tree boosting, to predict construction injury details, including injury type, energy type, and body part [43]. Another study used logistic regression, decision tree, random forest, and AdaBoost analysis machine learning methods to develop a predictive model to help prevent construction accidents [44]. To predict the safety climate in a construction site, another study developed a model based on an artificial neural network that assists clients and contractors in safely managing their construction sites by evaluating and predicting the safety climate [3]. Furthermore, in the context of the safety climate and its influence on safety behavior and safety performance, a study developed a prediction model by employing an artificial neural network to predict and evaluate workers' work behavior in construction sites using safety climate constructs [17].

The safety climate prediction model presented in this study is based on multiple factors that influence the safety climate in the context of Saudi Arabia. The model is intended to help industry stakeholders identify the overall safety climate level at a particular construction site. The model creates an opportunity to enhance safety levels by identifying areas of weakness and improvement based on employees' perceptions. This paper will contribute to safety climate research in the construction industry, specifically to the development of accident prediction models.

\section{Materials and Methods}

This study aims to develop a prediction model of observed safety climate levels by construction site personnel in the construction industry of Saudi Arabia. This includes exploring the set of predictors that can explain variations in construction sites' safety climates. Mosly and Makki [45] identified 13 safety-climate-influencing factors in Saudi Arabian construction sites (Table 1). Subsequently, Makki and Mosly conducted an exploratory study [46] that revealed that those influencing factors act as determinants of the safety climate under three key components (safety commitment, safety interaction, 
and safety support). This study builds upon these previous studies, using their safety climate determinants to explore the set of factors capable of predicting safety climate levels. Figure 1 presents the followed research framework and explains the association between the indicated previous studies (Phases I and II), respectively, and the study herein (Phase III). Furthermore, Figure 2 presents the general methodology flowchart used to attain the objective of this study, which is the development of the prediction model.

Table 1. Components and determinants of the safety climate in construction sites of Saudi Arabia.

\begin{tabular}{ccc}
\hline Component $^{\mathbf{a}}$ & & Determinant $^{\mathbf{b}}$ \\
\hline \multirow{3}{*}{ Safety commitment } & D1 & Workers' commitment to safety \\
& D2 & Appraisal of risks and hazards \\
& D3 & Management's commitment to safety \\
& D4 & Management's safety justice \\
D5 & Competence \\
\hline \multirow{3}{*}{ Safety interaction } & D6 & Workers' involvement \\
& D7 & Coworker influences \\
& D8 & Communication \\
Dafety support & D10 & Workers' attitude toward health and safety \\
& D11 & Supportive environment \\
\hline & D12 & Education and training \\
& D13 & Social security and health insurance \\
& Supervision, guidance, and inspection \\
\hline
\end{tabular}

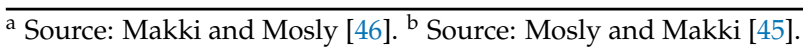

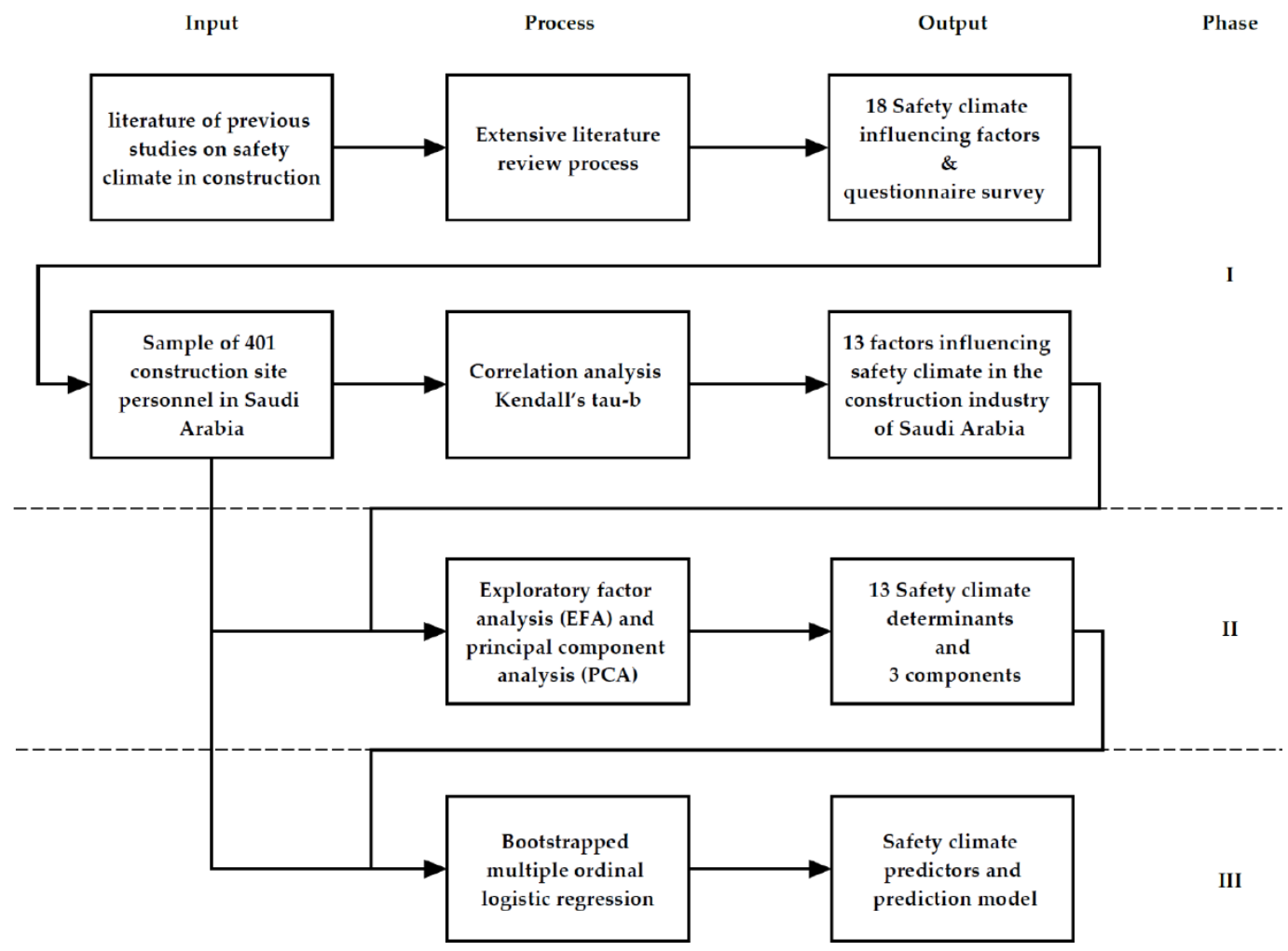

Figure 1. The research framework followed (Phase I: Mosly and Makki [45]; Phase II: Makki and Mosly [46]; and Phase III: the study herein). 


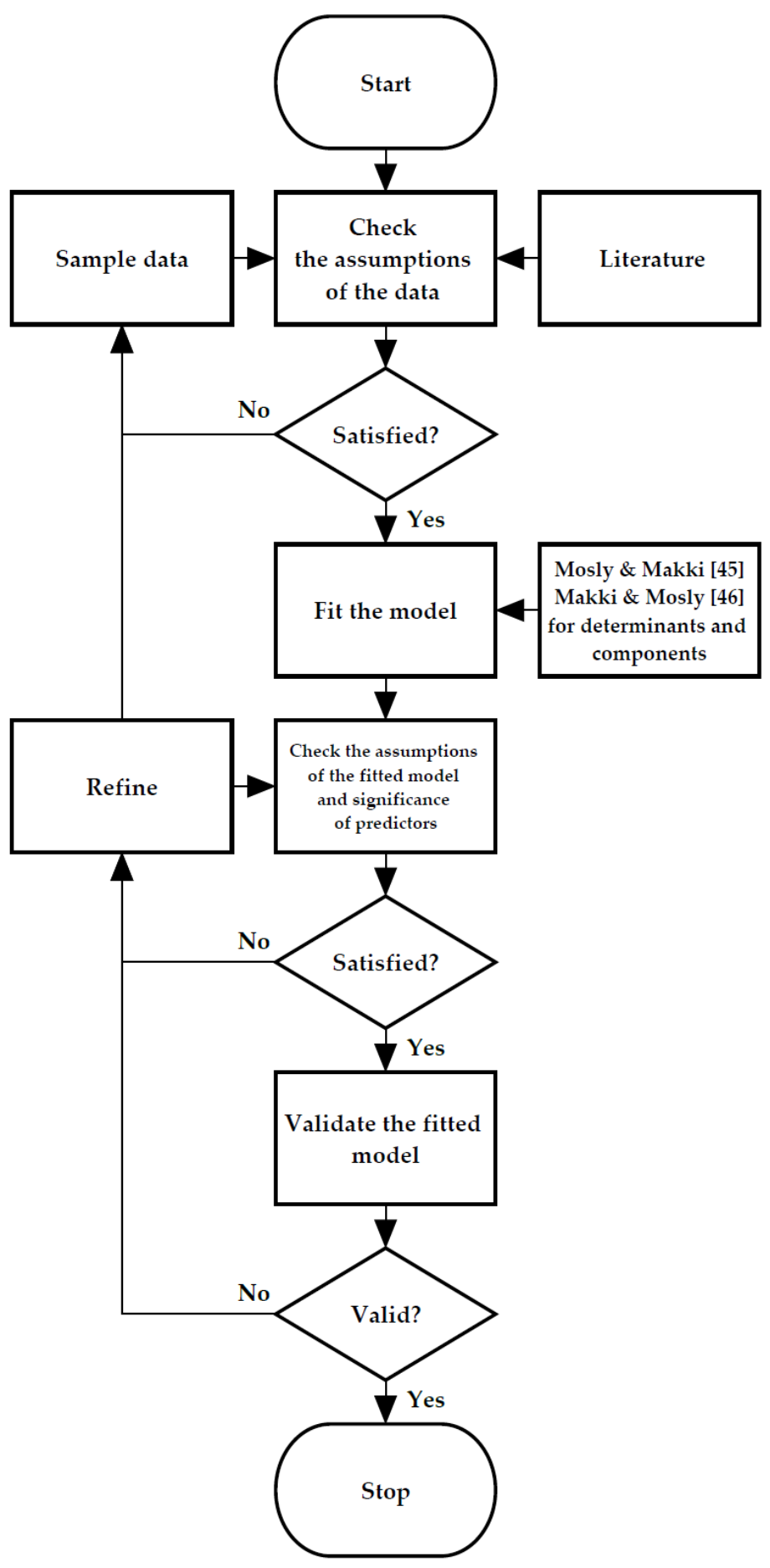

Figure 2. The general methodology flowchart used for prediction model development.

A questionnaire survey was used to ask $N=401$ construction site personnel working in ongoing (July 2019-January 2020) projects in Saudi Arabia to rate the importance of safety-climate-influencing factors, including the 13 determinants listed in Table 1. Respondents' perceptions were measured via questionnaire items on a five-point Likert scale (i.e., 5 = extremely important, 4 = important, 3 = neither, 2 = unimportant, 1 = extremely unimportant). Moreover, they were also asked to evaluate the overall construction site's safety climate on a five-point scale (i.e., $5=$ excellent, $4=$ good, $3=$ neither, 2 = poor, $1=$ extremely poor). However, for the purpose of this study, the construction sites' safety climate evaluations scores were reclustered into three categories (i.e., $3=$ excellent/good, 2 = neither, $1=$ poor/extremely poor). This ensured that the categories were mutually exclusive to 
analyze and interpret the results. More detailed information about the collected sample, such as questionnaire survey design, sampling process, targeted sample size, response rate, measurement scale, and descriptive statistics of the sample, including respondents' sociodemographic information, factors rating frequencies, the overall construction site's safety climate evaluation, and technical contents on the safety climate in the construction industry of Saudi Arabia, along with the used sample, can be found in a previous study by Mosly and Makki [45]. Full ethical approval of this study and the used questionnaire survey was granted by the Research Ethical Committee of the Center of Excellence in Genomic Medicine Research, King Abdulaziz University, (HA-02-J003).

An inferential statistical design was employed using the 13 safety climate determinants as independent variables (IVs) that predicted the construction site's safety climate evaluations, which served as the dependent variable (DV). Given that both the IVs and the DV were rated on the aforementioned scales, they were treated as discrete ordinal categorical variables. As appropriate for such a statistical design, a generalized linear model approach using multiple ordinal logistic regression was implemented.

Ordinal logistic regression is a maximum-likelihood-estimation-based method. It models proportional odds using a logit link function that performs logarithmic transformations of cumulative probabilities to express non-linear relationships between the IVs and DV in a linear model [47-52]. Accordingly, the Statistical Package for Social Sciences software (SPSS version 23.0) [53] was used to fit the following ordinal logit model in Equation (1):

$$
\operatorname{logit}\left(\gamma_{j}\right)=\ln \left(\frac{\gamma_{j}}{1-\gamma_{j}}\right)=\theta_{j}-\beta_{1} X_{1}+\beta_{2} X_{2}+\ldots+\beta_{k} X_{k}+\varepsilon,
$$

where

$j: 1$ to (number of DV categories -1 ),

$\gamma_{j}$ : cumulative probability for the $j$ th category,

$\theta_{j}$ : threshold for the $j$ th DV category,

$\beta_{1}$ to $\beta_{k}$ : regression coefficients of IVs,

$X_{1}$ to $X_{k}$ : IVs,

$k$ : number of IVs, and

$\varepsilon$ : error term.

Thus, by finding the antilog of Equation (1), the estimated regression model will be Equation (2) or (3):

$$
\begin{gathered}
\hat{\gamma}_{j}=e^{\theta_{j}-\left(\beta_{1} X_{1}+\beta_{2} X_{2}+\ldots+\beta_{k} X_{k}\right)} /\left(1+e^{\theta_{j}-\left(\beta_{1} X_{1}+\beta_{2} X_{2}+\ldots+\beta_{k} X_{k}\right)}\right), \\
\hat{\gamma}_{j}=1 /\left(1+e^{\left(-\theta_{j}+\beta_{1} X_{1}+\beta_{2} X_{2}+\ldots+\beta_{k} X_{k}\right)}\right),
\end{gathered}
$$

where $\hat{\gamma}_{j}$ is the estimated cumulative probability of a construction safety climate evaluation score based on the importance ratings of safety climate determinants, included in the model as predictors Xs and their associated $\beta$ s. Moreover, the odds and the odds ratio (OR) can be estimated by Equations (4) and (5), respectively, which also enables the estimation of the proportional change in the odds resulting from a unit change in the predictor (i.e., one score unit change in $X)$.

$$
\begin{gathered}
\text { Odds }=\gamma_{j} /\left(1-\gamma_{j}\right), \\
\text { OR }=\left(\text { Odds }_{\text {one score unit change }}\right) /\left(\text { Odds }_{\text {original score }}\right)
\end{gathered}
$$

Accordingly, the cumulative probability of observing a particular construction site safety climate evaluation score or a lower score can be estimated by modeling all odds following the form in Equation (6). Thus, the probabilities for the individual construction site safety climate evaluation scores (i.e., $P($ score $=j))$ can also be calculated using Equation $(7)$.

$$
\text { odds }=P(\text { score } \leq j) /(1-P(\text { score } \leq j)),
$$




$$
P(\text { score }=j)=P(\text { score } \leq j)-P(\text { score }<j)
$$

The decision to build the prediction model by entering the $13 \mathrm{IVs}$ as predictors and retaining the significant predictors was based on the principle of parsimony, as suggested by [3]. The IVs were entered in a stepwise hierarchical fashion based on the theory previously proven by Makki and Mosly [46] of their key component classifications as determinants (Table 1).

The overall fit of the model was tested using a $-2 \log$-likelihood $\chi^{2}$ statistic $\left(-2 \mathrm{LL} \chi^{2}\right)$ between the intercept-only model (i.e., baseline model) and the final model including the predictors (i.e., new model). The significance level $(p<0.05, p<0.01, p<0.001)$ of the safety climate determinants selected as IVs in predicting the construction site's safety climate evaluations as the DV was assessed using Equations (8) and (9).

$$
\begin{gathered}
\chi^{2}=2 L L_{\text {new }}-2 L L_{\text {baseline }}, \\
d f=k_{\text {new }}-k_{\text {baseline }}
\end{gathered}
$$

Moreover, a goodness-of-fit test using Pearson and deviance $\chi^{2}$ statistics was conducted. If the result is not significant (i.e., $p>0.05$ ), this test indicates that the model with the selected predictors is a good fit. Furthermore, to measure the strength of association between the selected set of IVs and the DV, the pseudo $R^{2}$ measures Cox and Snell $R^{2}$, Nagelkerke's $R^{2}$, and McFadden's $R^{2}$ were employed following Equations (10)-(12), respectively:

$$
\begin{gathered}
R_{\text {Cox and Snell }}^{2}=1-\left(L\left(B^{(0)}\right) / L(\hat{B})\right)^{\frac{2}{n}}, \\
R_{\text {Nagelkerke }}^{2}=R_{\text {Cox and Snell }}^{2} /\left(1-L\left(B^{(0)}\right)^{\frac{2}{n}}\right), \\
R_{\text {McFadden }}^{2}=1-\left(L(\hat{B}) / L\left(B^{(0)}\right)\right),
\end{gathered}
$$

where $\mathrm{L}(\hat{B})$ is the log-likelihood function for the model with the estimated parameters, $\mathrm{L}\left(\mathrm{B}^{(0)}\right)$ is the log-likelihood with just the thresholds, and $n$ is the number of cases (sum of all weights).

Moreover, to assess the significance level of each estimated regression model parameter, including thresholds (i.e., $\theta \mathrm{s}$ ) and predictor coefficients (i.e., $\beta \mathrm{s}$ ) and their associated standard errors (SEs) for each IV (i.e., location), the Wald $\chi^{2}$ statistic based on the $z$-statistic was constructed following Equations (13) and (14), respectively. The significance of each estimated parameter was measured on a $95 \%$ Wald confidence interval (CI). The same test was performed for the parameters' associated OR (i.e., $\exp (\theta, \beta)$ or $e^{\theta}$ and $e^{\beta}$ ).

$$
\begin{aligned}
& \text { Wald } \chi^{2}\left(\theta_{j}\right)=z^{2}=\left(\theta_{j} / S E_{\theta_{j}}\right)^{2}, \\
& \text { Wald } \chi^{2}\left(\beta_{k}\right)=z^{2}=\left(\beta_{k} / S E_{\beta_{k}}\right)^{2}
\end{aligned}
$$

Furthermore, to ensure the validity and accuracy of the results, the assumptions of the multiple ordinal logistic regression were checked and satisfied [47-52]. These assumptions include that the DV is measured on an ordinal level, which is the case in this study, given the DV measurement scale described above. Another assumption is that IVs are continuous, ordinal, and/or categorical variables, which is the case for all IVs using this scale. Moreover, the independence-of-observations assumption is satisfied in this study, as each data point comes from a different respondent. Furthermore, the assumption of proportionality or parallelism of odds for the final model was checked by conducting the test of parallel lines using the $-2 \mathrm{LL} \chi^{2}$ statistic. The result was insignificant (i.e., $p>0.05$ ), indicating that the location parameters of the regression model coefficients were the same across all the DV categories (in this case, DV scores). Another assumption is to ensure that there are no to low 
levels of multicollinearity between IVs. This was checked by correlation analysis between all IVs using Kendall's tau-b test statistics. This test reveals any signs of multicollinearity and guides the process of entering the IVs as predictors in the model in case there are proxy variables. Furthermore, the variance inflation factor (VIF) was calculated for each of the predictors retained in the final model; values close to 1 indicate low multicollinearity, while values close to 10 indicate that multicollinearity is a problem for the model [49]. Furthermore, linearity between IVs and the logit of DV was checked for the final model. An insignificant goodness-of-fit test $-2 \mathrm{LL} \chi^{2}$ statistic and an overall highly significant fit of the model based on the -2LL $\chi^{2}$ statistic comparing the intercept-only model and the final model was found. Additionally, each predictor's interactions in the final model and their log transformations were calculated and force-entered into the model, finding them to be insignificant. This is an indication satisfying the linearity assumption, according to Field [49]. Finally, sample size sufficiency was calculated using the rule-of-thumb formula in Equation (15), which is based on the concept of event per variable (EPV) [54].

$$
N_{E P V}=100+50 i,
$$

where $N_{E P V}$ is the estimated required sample size based on the EPV and $i$ is the number of IVs in the final model.

Sample size adequacy in this study was based on the number of retained predictors in the final model, $k=5$ and $N_{E P V}=100+50(5)=350$. Thus, the sample size used in this study, $N=401$ (>350), is sufficient, yielding a medium-to-large effect size [54]. In addition, another formula in Equation (16) was used for calculating the minimum sample size for logistic regression $[50,55]$ :

$$
N_{\text {min. }}=10 \mathrm{k} / \mathrm{q},
$$

where $N_{\min }$. is the minimum sample size for logistic regression, $q$ is the smallest of the proportions of negative or positive cases in the population, and $k$ is the number of IVs.

Based on the number of retained predictors in the final model in this study $(k=5)$, and the expected probability of the least frequent outcome $(q=0.2), N_{\min .}=10(5) / 0.2=250$ $(<N=401)$. Therefore, the sample size used in this study is also considered sufficient according to this formula.

Bootstrapping, a computer-intensive robust statistical inference approach recommended in the literature $[49,50,56]$, was used to ensure the final model's internal validity and the generalizability of its results. This technique empirically simulates the sample data's sampling distribution properties and checks whether the parameter estimates of the model (i.e., CIs and SEs of $\beta$ s) hold true after relaxing the distribution of the sample. In this study, a minimum bootstrap sample size of $B=1000$ was used by re-sampling individual data with replacement from the initial sampled dataset, which is considered reasonable for generating $95 \%$ bootstrap CI percentiles. However, since the IVs and the DV were all ordinal categorical variables in this study, the stratified sampling method for re-sampling each bootstrapped sample (i.e., each $B$ ) was used. This ensured that the simulated empirical distribution mimicked the structure of the collected sample dataset, under the assumption that it represents the population from which it was collected [57].

Finally, sensitivity analysis and scenario applications of the model were performed to confirm its validity. The application of described materials and methods and the resulted prediction model with its retained set of significant predictors are all presented and discussed below. Furthermore, to test the degree to which the probabilities predicted by the developed ordinal logistic regression model agree with actual observations in the collected dataset, the overall percentage of correct predictions was calculated. 


\section{Results and Discussion}

Data analysis was conducted using the above-described materials and methods. Before entering the 13 IVs (Table 1) in the model, Kendall's tau-b correlation analysis was performed between all safety climate determinants, as presented in the correlation matrix (Table 2). As mentioned earlier, this was to guide when entering the IVs as predictors in the model in case of proxy variables and served to reveal any violations of the multicollinearity assumption. Despite the significant correlations, none demonstrated a high correlation coefficient (i.e., 0.80 or higher). Therefore, no signs of multicollinearity between the IVs were detected. Nevertheless, the highest correlation coefficient (0.449) was found between determinants D7 (coworker influence) and D8 (communication). This indicates that these two determinants should be treated cautiously since they might represent each other to some extent if entered in the model as simultaneous predictors. The first criterion for inclusion in the model was to select the predicator that demonstrated a higher significance in explaining the variations in DV. Second, if both were significant, the predictor with a higher partial contribution when included with other predictors in the model was chosen, resulting in higher pseudo $R^{2}$ values of the overall model.

To build the prediction model, all 13 IVs were included in the model as covariate predictors against the DV. As mentioned earlier, the process of entering IVs was conducted in a stepwise hierarchical fashion based on the structure presented in Table 1. Through fitting the ordinal logit model present in Equation (1), five significant safety climate determinants (D13, D12, D3, D4, and D7, according to Table 1) were revealed as the predictors $\left(X_{1}, X_{2}\right.$, $X_{3}, X_{4}$, and $X_{5}$ ) of the construction site's safety climate levels, as evaluated by personnel (Tables 3 and 4 ).

To further check the multicollinearity assumption for the five predictors, the VIF for each predictor was calculated, as presented in Table 4. The VIF values ranged from 1.054 to 1.275 and were all relatively close to 1 , indicating that the prediction model satisfies the multicollinearity assumption. The overall fit of the model was tested using the $-2 \mathrm{LL} \chi^{2}$ statistic. Applying Equations (8) and (9), the difference between the baseline model and the new model including the five predictors was statistically significant: $\chi^{2}(5)=537.804-475.708=62.096$; $p<0.001$. Therefore, the model is considered a statistical fit. Moreover, the goodness-of-fit test indicated Pearson $\chi^{2}(425)=460.452301, p=0.114(>0.05)$, and deviance $\chi^{2}(425)=402.745$, $p=0.775(>0.05)$, indicating that the model is a good fit. Furthermore, the parallel lines test was performed using the $-2 \mathrm{LL} \chi^{2}$ statistic to test the difference between the null hypothesis that the model is based on proportional odds and the alternative hypothesis of nonproportional odds. The results showed that $\chi^{2}(5)=475.708-472.788=2.920, p=0.712(>0.05)$, indicating that the location parameters of the model are the same across all response categories. Thus, the model satisfied the assumption of proportionality or parallelism of odds. Moreover, to measure the strength of association between the five IVs and the DV using Equations (10-12), the model demonstrated acceptable levels of pseudo $R^{2} \mathrm{~s}$ : Cox and Snell $=0.143$, Nagelkerke $=0.178$, and McFadden $=0.095$, respectively.

As presented in Table 4, all estimated regression model parameters, including the model thresholds (i.e., $\theta_{1}$ and $\theta_{2}$ ) and the location predictor coefficients (i.e., $\beta_{1}-\beta_{5}$ ), were significant. This was measured using Wald $\chi^{2}$ statistics, which were obtained using Equations (13) and (14). Moreover, estimated regression model parameters demonstrated reasonable SE and bias levels on both $95 \%$ Wald CIs and $95 \%$ bootstrapped CIs.

The positive values of the location predictor coefficients (i.e., $\beta_{1}-\beta_{5}$ ), along with the fact that their associated $\exp (\beta)$ values were greater than 1 , indicates higher odds of moving to a higher ordered category in the DV for a higher value in any of the IVs (i.e., $X_{1}, X_{2}, X_{3}$, $X_{4}$, or $\left.X_{5}\right)$ by one unit. The OR value of $\exp (\beta)$ associated with each predictor indicates the magnitude (i.e., how many times) of the increase. Thus, in Tables 3 and 4 , the predictors are ordered on that basis. 
Table 2. Kendall's tau-b correlation matrix of safety climate determinants.

\begin{tabular}{|c|c|c|c|c|c|c|c|c|c|c|c|c|c|}
\hline Determinant & D1 & D2 & D3 & D4 & D5 & D6 & D7 & D8 & D9 & D10 & D11 & D12 & D13 \\
\hline D1 & 1.000 & $0.350 * *$ & $0.379 * *$ & $0.380 * *$ & $0.225^{* *}$ & 0.015 & -0.019 & 0.053 & $0.127 * *$ & 0.065 & $0.279^{* *}$ & $0.101 *$ & $0.303^{* *}$ \\
\hline D2 & & 1.000 & $0.286^{* *}$ & $0.342^{* *}$ & $0.261^{* *}$ & $0.178^{* *}$ & 0.094 * & 0.076 & $0.195^{* *}$ & $0.116^{* *}$ & $0.256^{* *}$ & $0.116^{* *}$ & $0.293^{* *}$ \\
\hline D3 & & & 1.000 & $0.366^{* *}$ & $0.186^{* *}$ & 0.066 & 0.047 & $0.132 * *$ & 0.079 & $0.134 * *$ & $0.272 * *$ & $0.092 *$ & $0.294^{* *}$ \\
\hline D4 & & & & 1.000 & $0.179 * *$ & 0.007 & -0.021 & 0.059 & 0.081 & $0.135^{* *}$ & $0.284^{* *}$ & $0.210^{* *}$ & $0.296^{* *}$ \\
\hline D5 & & & & & 1.000 & $0.122 * *$ & 0.062 & $0.124^{* *}$ & $0.234^{* *}$ & $0.178^{* *}$ & $0.154^{* *}$ & $0.094 *$ & $0.189^{* *}$ \\
\hline D6 & & & & & & 1.000 & $0.408^{* *}$ & $0.318^{* *}$ & $0.350 * *$ & $0.293^{* *}$ & -0.035 & $0.126^{* *}$ & 0.052 \\
\hline D7 & & & & & & & 1.000 & $0.449 * *$ & $0.299 * *$ & $0.221^{* *}$ & 0.050 & $0.166^{* *}$ & 0.072 \\
\hline D8 & & & & & & & & 1.000 & $0.265^{* *}$ & $0.186^{* *}$ & 0.071 & $0.159^{* *}$ & 0.109 * \\
\hline D9 & & & & & & & & & 1.000 & $0.221^{* *}$ & 0.037 & $0.122^{* *}$ & $0.132 * *$ \\
\hline D10 & & & & & & & & & & 1.000 & 0.071 & $0.181^{* *}$ & $0.146^{* *}$ \\
\hline D11 & & & & & & & & & & & 1.000 & $0.156^{* *}$ & $0.413^{* *}$ \\
\hline D12 & & & & & & & & & & & & 1.000 & $0.161^{* *}$ \\
\hline D13 & & & & & & & & & & & & & 1.000 \\
\hline
\end{tabular}


Table 3. Construction site safety climate predictors retained in the prediction model.

\begin{tabular}{ccc}
\hline Component & & Predictor \\
\hline \multirow{2}{*}{ Safety support } & $X_{1}$ & Supervision, guidance, and inspection \\
& $X_{2}$ & Social security and health insurance \\
\hline \multirow{2}{*}{ Safety commitment } & $X_{3}$ & Management's commitment to safety \\
& $X_{4}$ & Management's safety justice \\
\hline Safety interaction & $X_{5}$ & Coworker influences \\
\hline
\end{tabular}

After satisfying the assumptions of the ordinal logistic regression model and given the statistical significance of the fit of the model, its goodness-of-fit, and the model parameter estimations, the prediction model with the selected predictors was deemed the final model. Therefore, using the models in Table 4 and Equation (1), the final fitted ordinal logistic model is described by Equation (17).

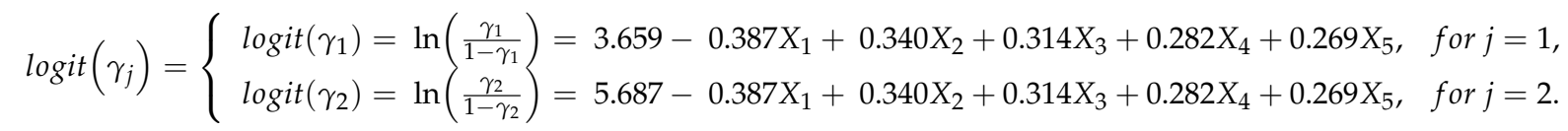

According to Equations (2) and (3), and given that the cumulative probability of all three DV categories (i.e., 3 = excellent/good, 2 = neither, 1 = poor/extremely poor) is 1 , the cumulative probabilities of the first DV category (i.e., poor/extremely poor) for any value combinations (i.e., $X_{1}, X_{2}, X_{3}, X_{4}$, and $X_{5}$ ) ranging from 1 to 5 (i.e., $5=$ extremely important, 4 = important, 3 = neither, 2 = unimportant, 1 = extremely unimportant) can be estimated using Equation (18) or (19).

$$
\begin{gathered}
\hat{\gamma}_{1}=\left(e^{3.659-\left(0.387 X_{1}+0.340 X_{2}+0.314 X_{3}+0.282 X_{4}+0.269 X_{5}\right)}\right) /\left(1+e^{3.659-\left(0.387 X_{1}+0.340 X_{2}+0.314 X_{3}+0.282 X_{4}+0.269 X_{5}\right)}\right), \\
\hat{\gamma}_{1}=1 /\left(1+e^{\left(-3.659+0.387 X_{1}+0.340 X_{2}+0.314 X_{3}+0.282 X_{4}+0.269 X_{5}\right)}\right)
\end{gathered}
$$

Similarly, the cumulative probabilities of the second category of the DV (i.e., neither or poor/extremely poor) can be estimated using Equation (20) or (21).

$$
\begin{gathered}
\hat{\gamma}_{2}=\left(e^{5.687-\left(0.387 X_{1}+0.340 X_{2}+0.314 X_{3}+0.282 X_{4}+0.269 X_{5}\right)}\right) /\left(1+e^{3.659-\left(0.387 X_{1}+0.340 X_{2}+0.314 X_{3}+0.282 X_{4}+0.269 X_{5}\right)}\right), \\
\hat{\gamma}_{2}=1 /\left(1+e^{\left(-5.687+0.387 X_{1}+0.340 X_{2}+0.314 X_{3}+0.282 X_{4}+0.269 X_{5}\right)}\right)
\end{gathered}
$$

Accordingly, the odds and odds ratio can be directly calculated using Equations (4)(6), respectively. The individual probabilities of each of the three DV scores following Equation (7) can be calculated using Equations (22)-(24), respectively.

$$
\begin{array}{r}
P(\text { score }=1)=P(\text { score } \leq 1)-P(\text { score }<1)=P(\text { score } \leq 1)-0, \\
P(\text { score }=2)=P(\text { score } \leq 2)-P(\text { score }<2)=P(\text { score }=1 \text { or } 2)-P(\text { score }=1), \\
P(\text { score }=3)=P(\text { score } \leq 3)-P(\text { score }<3)=P(\text { score }=1 \text { or } 2 \text { or } 3)-P(\text { score }=1 \text { or } 2)
\end{array}
$$


Table 4. Bootstrapped ordinal logistic regression model $(N=401)$.

\begin{tabular}{|c|c|c|c|c|c|c|c|c|c|c|c|c|c|c|}
\hline \multirow{2}{*}{\multicolumn{2}{|c|}{ Parameter }} & \multirow{3}{*}{$\theta, \beta$} & \multirow{3}{*}{ SE } & \multirow{2}{*}{\multicolumn{2}{|c|}{ 95\% Wald CI }} & \multirow{3}{*}{ Wald $\chi^{2 \mathrm{a}}$} & \multirow{3}{*}{$\begin{array}{c}\operatorname{Exp} \\
(\theta, \beta)\end{array}$} & \multirow{2}{*}{\multicolumn{2}{|c|}{$\begin{array}{c}95 \% \text { Wald CI for } \\
\operatorname{Exp}(\theta, \beta)\end{array}$}} & \multirow{3}{*}{ Bias } & \multirow{2}{*}{\multicolumn{3}{|c|}{ Bootstrap $^{b}$}} & \multirow{3}{*}{ VIF $^{c}$} \\
\hline & & & & & & & & & & & & & & \\
\hline & & & & Lower & Upper & & & Lower & Upper & & & Lower & Upper & \\
\hline \multirow[b]{2}{*}{ Threshold } & $\theta_{1}$ & 3.659 & 0.839 & 2.015 & 5.304 & $19.027^{* * *}$ & 38.839 & 7.502 & 201.075 & 0.030 & 0.482 & 2.734 & 4.650 & - \\
\hline & $\theta_{2}$ & 5.687 & 0.868 & 3.985 & 7.388 & $42.908^{* * *}$ & 294.862 & 53.787 & 1616.445 & 0.041 & 0.497 & 4.761 & 6.699 & - \\
\hline \multirow{5}{*}{ Location } & $X_{1}$ & 0.387 & 0.143 & 0.106 & 0.668 & $7.270^{* *}$ & 1.472 & 1.111 & 1.949 & 0.005 & 0.071 & 0.259 & 0.543 & 1.223 \\
\hline & $X_{2}$ & 0.340 & 0.124 & 0.098 & 0.582 & $7.586^{* *}$ & 1.405 & 1.103 & 1.790 & 0.001 & 0.062 & 0.218 & 0.464 & 1.128 \\
\hline & $X_{3}$ & 0.314 & 0.135 & 0.050 & 0.578 & $5.423 *$ & 1.369 & 1.051 & 1.783 & 0.002 & 0.066 & 0.181 & 0.444 & 1.265 \\
\hline & $X_{4}$ & 0.282 & 0.122 & 0.043 & 0.521 & $5.353 *$ & 1.326 & 1.044 & 1.684 & 0.000 & 0.060 & 0.167 & 0.397 & 1.275 \\
\hline & $X_{5}$ & 0.269 & 0.118 & 0.039 & 0.499 & $5.241 *$ & 1.309 & 1.039 & 1.647 & 0.003 & 0.063 & 0.149 & 0.398 & 1.054 \\
\hline
\end{tabular}

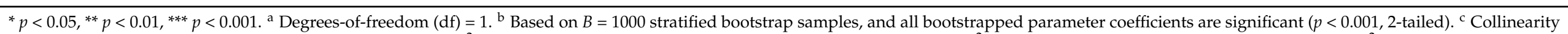

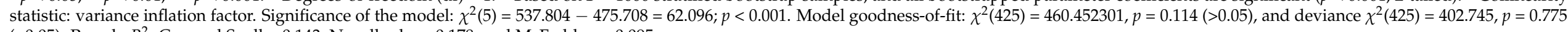
$(>0.05)$. Pseudo $R^{2}:$ Cox and Snell $=0.143$, Nagelkerke $=0.178$, and McFadden $=0.095$. 
To test the model's validity, sensitivity analysis and scenario applications were performed. As presented in Table 5, five extreme scenarios were applied using the prediction model. In the first scenario, all predictor values were set to 1 , representing a scenario in which the model user rated the importance of all five safety climate predictors to be extremely unimportant as a safety climate determinant. The remaining four scenarios followed the same pattern for the values 2, 3, 4, and 5, respectively; in each scenario, all predictors were set to the same value, with the final scenario representing a model user who rated all predicators as extremely important. This procedure tested whether the model could assign higher probability percentages to higher scores on the DV. Accordingly, using Equations (17)-(24), and as presented in Table 5, the model successfully predicted the scores of the construction site's safety climate evaluations based on the importance ratings of safety climate determinants. This can be observed from the higher estimated score probability percentages shown in bold font (Table 5). The model also demonstrated the odds ratios' proportionality, having an equal OR value of 0.132 , as shown in Table 5. Similarly, any combination of values ranging from 1 to 5 on the importance scale described above can be substituted in the five model predictors (i.e., $X_{1}, X_{2}, X_{3}, X_{4}$, or $X_{5}$ ) to estimate the safety climate evaluations. The developed prediction model correctly predicted $67 \%$ of the 401 safety climate evaluations of the construction site based on which it was modeled.

Table 5. Sensitivity analysis and scenario applications of the developed prediction model.

\begin{tabular}{|c|c|c|c|c|c|c|}
\hline Scenario & IV Scores ${ }^{a}$ & $\begin{array}{c}\text { Type of DV Score } \\
\text { Probability }\end{array}$ & $\begin{array}{l}\text { DV Score } \\
\text { Probability }\end{array}$ & $\begin{array}{c}\text { DV Estimated Score } \\
\text { Probability }\end{array}$ & $\%$ & OR \\
\hline \multirow{6}{*}{1} & \multirow{6}{*}{$\begin{array}{l}X_{1}=1 \\
X_{2}=1 \\
X_{3}=1 \\
X_{4}=1 \\
X_{5}=1\end{array}$} & \multirow{3}{*}{ cumulative } & $P($ Score $\leq 1)$ & 0.888 & 88.77 & \multirow{6}{*}{0.132} \\
\hline & & & $P($ Score $\leq 2)$ & 0.984 & 98.36 & \\
\hline & & & $P($ Score $\leq 3)$ & 1 & 100 & \\
\hline & & \multirow{3}{*}{ individual } & $P($ Score $=1)$ & 0.888 & 88.77 & \\
\hline & & & $P($ Score $=2)$ & 0.096 & 9.59 & \\
\hline & & & $P($ Score $=3)$ & 0.016 & 1.64 & \\
\hline \multirow{6}{*}{2} & \multirow{6}{*}{$\begin{array}{l}X_{1}=2 \\
X_{2}=2 \\
X_{3}=2 \\
X_{4}=2 \\
X_{5}=2\end{array}$} & \multirow{3}{*}{ cumulative } & $P($ Score $\leq 1)$ & 0.617 & 61.67 & \multirow{6}{*}{0.132} \\
\hline & & & $P($ Score $\leq 2)$ & 0.924 & 92.43 & \\
\hline & & & $P($ Score $\leq 3)$ & 1 & 100 & \\
\hline & & \multirow{3}{*}{ individual } & $P($ Score $=1)$ & 0.617 & 61.67 & \\
\hline & & & $P($ Score $=2)$ & 0.308 & 30.76 & \\
\hline & & & $P($ Score $=3)$ & 0.076 & 7.57 & \\
\hline \multirow{6}{*}{3} & \multirow{6}{*}{$\begin{array}{l}X_{1}=3 \\
X_{2}=3 \\
X_{3}=3 \\
X_{4}=3 \\
X_{5}=3\end{array}$} & \multirow{3}{*}{ cumulative } & $P($ Score $\leq 1)$ & 0.247 & 24.67 & \multirow{6}{*}{0.132} \\
\hline & & & $P($ Score $\leq 2)$ & 0.713 & 71.32 & \\
\hline & & & $P($ Score $\leq 3)$ & 1 & 100 & \\
\hline & & \multirow{3}{*}{ individual } & $P($ Score $=1)$ & 0.247 & 24.67 & \\
\hline & & & $P($ Score $=2)$ & 0.466 & 46.65 & \\
\hline & & & $P($ Score $=3)$ & 0.287 & 28.68 & \\
\hline \multirow{6}{*}{4} & \multirow{6}{*}{$\begin{array}{l}X_{1}=4 \\
X_{2}=4 \\
X_{3}=4 \\
X_{4}=4 \\
X_{5}=4\end{array}$} & \multirow{3}{*}{ cumulative } & $P($ Score $\leq 1)$ & 0.062 & 6.25 & \multirow{6}{*}{0.132} \\
\hline & & & $P($ Score $\leq 2)$ & 0.336 & 33.60 & \\
\hline & & & $P($ Score $\leq 3)$ & 1 & 100 & \\
\hline & & \multirow{3}{*}{ individual } & $P($ Score $=1)$ & 0.062 & 6.25 & \\
\hline & & & $P($ Score $=2)$ & 0.274 & 27.35 & \\
\hline & & & $P($ Score $=3)$ & 0.664 & 66.40 & \\
\hline \multirow{6}{*}{5} & \multirow{6}{*}{$\begin{array}{l}X_{1}=5 \\
X_{2}=5 \\
X_{3}=5 \\
X_{4}=5 \\
X_{5}=5\end{array}$} & \multirow{3}{*}{ cumulative } & $P($ Score $\leq 1)$ & & 1.34 & \multirow{6}{*}{0.132} \\
\hline & & & $P($ Score $\leq 2)$ & 0.093 & 9.34 & \\
\hline & & & $P($ Score $\leq 3)$ & & 100 & \\
\hline & & \multirow{3}{*}{ individual } & $P($ Score $=1)$ & 0.013 & 1.34 & \\
\hline & & & $P($ Score $=2)$ & 0.080 & 8.00 & \\
\hline & & & $P($ Score $=3)$ & 0.907 & 90.66 & \\
\hline
\end{tabular}

a IVs scores: 5 = excellent, 4 = good, 3 = neither, 2 = poor, and 1 = extremely poor, representing importance ratings of the five safety climate determinants retained in the prediction model as predictors (Table 3 ). ${ }^{b}$ DV scores: $3=$ excellent/good, $2=$ neither, and $1=$ poor/extremely poor, representing the predicted construction site safety climate evaluation level. The italicized font represents the highest likelihood percentages. 
Finally, the novelty of the prediction model developed in this study lies in the modeling process following the bootstrapped multiple ordinal logistic regression approach, which revealed five significant predictors that are part of the most significant determinants that cluster under the three main safety climate components: safety support, safety commitment, and safety interaction (Table 3). This underlines the importance of these three key components in construction sites and their impact on construction personnel's evaluations of the safety climate. Moreover, the developed prediction model provides an instrument that can help construction industry decision makers, safety policy designers, government agencies, and stakeholders to estimate the safety climate of construction sites and determine areas of improvement. This is through plugging in importance rating values by personnel at a construction site in the model using the aforementioned scale to predict the probability of its safety climate evaluation scores. This can assist in determining and addressing low-scoring predictors that can translate to safety performance improvements.

\section{Conclusions}

In this study, a model to predict observed safety climate levels by construction site personnel working in the construction industry of Saudi Arabia was developed. Significant predictors of the safety climate in construction sites were identified. The prediction model was developed using the bootstrapped multiple ordinal logistic regression statistical technique. The model revealed five statistically significant predictors: supervision, guidance, and inspection; social security and health insurance; management's commitment to safety; management's safety justice; and coworker influence. These predictors were classified under the three components of safety climate determinants: safety support, safety commitment, and safety interaction. A sensitivity analysis and scenario application showed that the model is responsive to extreme higher and lower input values and reflects them in the predicted output. Furthermore, the developed model can generate $67 \%$ correct predictions using the revealed set of predictors. Applications of the prediction model include assisting construction industry decision makers, safety policy designers, government agencies, and stakeholders to estimate construction site safety climates and determine areas of improvement. Targeting improvements for low-scoring predictors can translate to safety performance improvements.

Collecting a larger sample size and reapplying this study's methodology is a possible direction for future research. This approach could confirm the revealed set of predictors using another dataset. Other machine learning prediction or classification techniques could also be used in future studies to confirm the set of predictors and improve prediction accuracy. The prediction model developed in this study represents patterns within the study's dataset describing the construction industry of Saudi Arabia. Conducting a similar study in other temporal and spatial contexts would also be a worthy topic of future research.

Author Contributions: Conceptualization, A.A.M. and I.M.; methodology, A.A.M. and I.M.; software, A.A.M.; validation, A.A.M. and I.M.; formal analysis, A.A.M.; investigation, A.A.M. and I.M.; resources, A.A.M. and I.M.; data curation, A.A.M. and I.M.; writing-original draft preparation, A.A.M. and I.M.; writing-review and editing, A.A.M. and I.M.; visualization, A.A.M. and I.M.; supervision, A.A.M. and I.M.; project administration, A.A.M. and I.M. All authors have read and agreed to the published version of the manuscript.

Funding: This research received no external funding.

Institutional Review Board Statement: Full ethical approval of this study was granted by the Research Ethical Committee of the Center of Excellence in Genomic Medicine Research, King Abdulaziz University, (HA-02-J003).

Informed Consent Statement: Informed consent was obtained from all subjects involved in the study.

Data Availability Statement: The data presented in this study are available on request from the corresponding author. The data are not publicly available due to privacy and ethical restrictions. 
Acknowledgments: The authors acknowledge and thank the respondents of the survey questionnaire in this research study.

Conflicts of Interest: The authors declare no conflict of interest.

\section{References}

1. Kang, K.; Ryu, H. Predicting types of occupational accidents at construction sites in Korea using random forest model. Saf. Sci. 2019, 120, 226-236. [CrossRef]

2. Mohammadi, A.; Tavakolan, M. Modeling the effects of production pressure on safety performance in construction projects using system dynamics. J. Saf. Res. 2019, 71, 273-284. [CrossRef]

3. Patel, D.; Jha, K. Neural Network Approach for Safety Climate Prediction. J. Manag. Eng. 2014, 31, 05014027. [CrossRef]

4. Newaz, M.; Davis, P.; Jefferies, M.; Pillay, M. Developing a safety climate factor model in construction research and practice: A systematic review identifying future directions for research. Eng. Constr. Archit. Manag. 2018, 25, 738-757. [CrossRef]

5. Chen, Y.; McCabe, B.; Hyatt, D. A resilience safety climate model predicting construction safety performance. Saf. Sci. 2018, 109, 434-445. [CrossRef]

6. Mosly, I. Factors Influencing Safety Climate in the Construction Industry: A Review. Int. J. Constr. Eng. Manag. 2019, 8, 105-109. [CrossRef]

7. Kim, N.; Rahim, N.A.; Iranmanesh, M.; Foroughi, B. The role of the safety climate in the successful implementation of safety management systems. Saf. Sci. 2019, 118, 48-56. [CrossRef]

8. Loosemore, M.; Sunindijo, R.; Zhang, S. Comparative Analysis of Safety Climate in the Chinese, Australian, and Indonesian Construction Industries. J. Constr. Eng. Manag. 2020, 146, 04020129. [CrossRef]

9. Winge, S.; Albrechtsen, E.; Arnesen, J. A comparative analysis of safety management and safety performance in twelve construction projects. J. Saf. Res. 2019, 71, 139-152. [CrossRef]

10. Elmoujaddidi, F.; Bachir, A. Perceived risk, safety climate and safety behavior on Moroccan construction sites. Int. J. Occup. Saf. Ergon. 2020, 26, 121-128. [CrossRef]

11. Wu, C.; Luo, X.; Wang, T.; Wang, Y.; Sapkota, B. Safety challenges and improvement strategies of ethnic minority construction workers: A case study in Hong Kong. Int. J. Occup. Saf. Ergon. 2020, 26, 80-90. [CrossRef] [PubMed]

12. Choudhry, R.; Fang, D.; Lingard, H. Measuring Safety Climate of a Construction Company. J. Constr. Eng. Manag. 2009, 135, 890-899. [CrossRef]

13. Zahoor, H.; Chan, A.; Utama, W.; Gao, R.; Zafar, I. Modeling the Relationship between Safety Climate and Safety Performance in a Developing Construction Industry: A Cross-Cultural Validation Study. Int. J. Environ. Res. Public Health 2017, 14, 351. [CrossRef] [PubMed]

14. Lyu, S.; Hon, C.; Chan, A.; Wong, F.; Javed, A. Relationships among Safety Climate, Safety Behavior, and Safety Outcomes for Ethnic Minority Construction Workers. Int. J. Environ. Res. Public Health 2018, 15, 484. [CrossRef]

15. Johnson, S. The predictive validity of safety climate. J. Saf. Res. 2007, 38, 511-521. [CrossRef]

16. Patel, D.; Jha, K. Neural Network Model for the Prediction of Safe Work Behavior in Construction Projects. J. Constr. Eng. Manag. 2015, 141, 04014066. [CrossRef]

17. Patel, D.; Jha, K. Evaluation of construction projects based on the safe work behavior of co-employees through a neural network model. Saf. Sci. 2016, 89, 240-248. [CrossRef]

18. Han, Y.; Yin, Z.; Liu, J.; Jin, R.; Gidado, K.; Painting, N.; Yang, Y.; Yan, L. Defining and Testing a Safety Cognition Framework Incorporating Safety Hazard Perception. J. Constr. Eng. Manag. 2019, 145, 04019081. [CrossRef]

19. Stackhouse, M.; Turner, N. How do organizational practices relate to perceived system safety effectiveness? Perceptions of safety climate and co-worker commitment to safety as workplace safety signals. J. Saf. Res. 2019, 70, 59-69. [CrossRef]

20. Nielsen, K.; Grytnes, R.; Dyreborg, J. Pilot test of a tailored intervention to improve apprentice safety in small construction companies. Saf. Sci. 2019, 117, 305-313. [CrossRef]

21. Khoshnava, S.; Rostami, R.; Zin, R.; Mishra, A.; Rani, P.; Mardani, A.; Alrasheedi, M. Assessing the impact of construction industry stakeholders on workers' unsafe behaviours using extended decision making approach. Autom. Constr. 2020, 118, 103162. [CrossRef]

22. Probst, T.; Goldenhar, L.; Byrd, J.; Betit, E. The Safety Climate Assessment Tool (S-CAT): A rubric-based approach to measuring construction safety climate. J. Saf. Res. 2019, 69, 43-51. [CrossRef] [PubMed]

23. Shohet, I.; Luzi, M.; Tarshish, M. Optimal allocation of resources in construction safety: Analytical-empirical model. Saf. Sci. 2018, 104, 231-238. [CrossRef]

24. Marín, L.; Lipscomb, H.; Cifuentes, M.; Punnett, L. Perceptions of safety climate across construction personnel: Associations with injury rates. Saf. Sci. 2019, 118, 487-496. [CrossRef]

25. Xia, N.; Xie, Q.; Hu, X.; Wang, X.; Men, H. A dual perspective on risk perception and its effect on safety behavior: A moderated mediation model of safety motivation, and supervisor's and coworkers' safety climate. Accid. Anal. Prev. 2020, 134, 105350. [CrossRef] [PubMed]

26. He, C.; McCabe, B.; Jia, G.; Sun, J. Effects of Safety Climate and Safety Behavior on Safety Outcomes between Supervisors and Construction Workers. J. Constr. Eng. Manag. 2020, 146, 04019092. [CrossRef] 
27. Pandit, B.; Albert, A.; Patil, Y.; Al-Bayati, A. Impact of safety climate on hazard recognition and safety risk perception. Saf. Sci. 2019, 113, 44-53. [CrossRef]

28. Low, B.; Man, S.; Chan, A.; Alabdulkarim, S. ConstructionWorker Risk-Taking Behavior Model with Individual and Organizational Factors. Int. J. Environ. Res. Public Health 2019, 16, 1335. [CrossRef]

29. Meng, X.; Chan, A.; Lui, L.; Fang, Y. Effects of individual and organizational factors on safety consciousness and safety citizenship behavior of construction workers: A comparative study between Hong Kong and Mainland China. Saf. Sci. 2021, 135, 105116. [CrossRef]

30. Dale, A.; Colvin, R.; Barrera, M.; Strickland, J.; Evanoff, B. The association between subcontractor safety management programs and worker perceived safety climate in commercial construction projects. J. Saf. Res. 2020, 74, 279-288. [CrossRef] [PubMed]

31. Schwatka, N.; Goldenhar, L.; Johnson, S.; Beldon, M.; Tessler, J.; Dennerlein, J.; Fullen, M.; Trieu, H. A training intervention to improve frontline construction leaders' safety leadership practices and overall jobsite safety climate. J. Saf. Res. 2019, 70, 253-262. [CrossRef]

32. Schwatka, N.; Goldenhar, L.; Johnson, S. Change in frontline supervisors' safety leadership practices after participating in a leadership training program: Does company size matter? J. Saf. Res. 2020, 74, 199-205. [CrossRef]

33. Goldenhar, L.; Schwatka, N.; Johnson, S. Leadership skills for strengthening jobsite safety climate. J. Saf. Res. 2019, 70, 263-271. [CrossRef]

34. Shohet, I.; Wei, H.; Skibniewski, M.; Tak, B.; Revivi, M. Integrated Communication, Control, and Command of Construction Safety and Quality. J. Constr. Eng. Manag. 2019, 145, 04019051. [CrossRef]

35. Zamani, V.; Banihashemi, S.; Abbasi, A. How can communication networks among excavator crew members in construction projects affect the relationship between safety climate and safety outcomes? Saf. Sci. 2020, 128, 104737. [CrossRef]

36. Pandit, B.; Albert, A.; Patil, Y. Developing construction hazard recognition skill: Leveraging safety climate and social network safety communication patterns. Constr. Manag. Econ. 2020, 38, 640-658. [CrossRef]

37. Esmaeili, B.; Hallowell, M.; Rajagopalan, B. Attribute-Based Safety Risk Assessment. II: Predicting Safety Outcomes Using Generalized Linear Models. J. Constr. Eng. Manag. 2015, 141, 04015022. [CrossRef]

38. Hallowell, M.; Bhandari, S.; Alruqi, W. Methods of safety prediction: Analysis and integration of risk assessment, leading indicators, precursor analysis, and safety climate. Constr. Manag. Econ. 2020, 38, 308-321. [CrossRef]

39. Panuwatwanich, K.; Al-Haadir, S.; Stewart, R. Influence of safety motivation and climate on safety behaviour and outcomes: Evidence from the Saudi Arabian construction industry. Int. J. Occup. Saf. Ergon. 2017, 23, 60-75. [CrossRef] [PubMed]

40. Jiang, L.; Lavaysse, L.; Probst, T. Safety climate and safety outcomes: A meta-analytic comparison of universal vs. industry-specific safety climate predictive validity. Work Stress 2019, 33, 41-57. [CrossRef]

41. Chang, Y.; Lee, S.; Liu, P.; Chang, C. Injury Prediction Based on Safety Climate Questionnaire Score Using Artificial Neural Networks. In Proceedings of the 2017 IEEE International Conference on Industrial Engineering and Engineering Management (IEEM), Singapore, 10-13 December 2017.

42. Su, Y.; Yang, S.; Liu, K.; Hua, K.; Yao, Q. Developing A Case-Based Reasoning Model for Safety Accident Pre-Control and Decision Making in the Construction Industry. Int. J. Environ. Res. Public Health 2019, 16, 1511. [CrossRef] [PubMed]

43. Tixier, A.; Hallowell, M.; Rajagopalan, B.; Bowman, D. Application of machine learning to construction injury prediction. Autom. Constr. 2016, 69, 102-114. [CrossRef]

44. Choi, J.; Gu, B.; Chin, S.; Lee, J. Machine learning predictive model based on national data for fatal accidents of construction workers. Autom. Constr. 2020, 110, 102974. [CrossRef]

45. Mosly, I.; Makki, A. Safety Climate Perceptions in the Construction Industry of Saudi Arabia: The Current Situation. Int. J. Environ. Res. Public Health 2020, 17, 6717. [CrossRef]

46. Makki, A.; Mosly, I. Determinants for Safety Climate Evaluation of Construction Industry Sites in Saudi Arabia. Int. J. Environ. Res. Public Health 2020, 17, 8225. [CrossRef]

47. O'Connell, A. Logistic Regression Models for Ordinal Response Variables; Sage: Thousand Oaks, CA, USA, 2006.

48. Harrell, F. Ordinal Logistic Regression. In Regression Modeling Strategies; Springer: Cham, Switzerland, 2015; pp. 311-325. [CrossRef]

49. Field, A. Discovering Statistics Using IBM SPSS Statistics, 5th ed.; SAGE Publications Ltd.: London, UK, 2018.

50. Park, H. An introduction to logistic regression: From basic concepts to interpretation with particular attention to nursing domain. J. Korean Acad. Nurs. 2013, 43, 154-164. [CrossRef]

51. Bewick, V.; Cheek, L.; Ball, J. Statistics review 13: Receiver operating characteristic curves. Crit. Care 2004, 8, 508-512. [CrossRef]

52. Peng, C.; So, T. Logistic regression analysis and reporting: A primer. Underst. Stat. 2002, 1, 31-70. [CrossRef]

53. IBM. IBM SPSS Statistics for Windows, Version 23.0; IBM Corp: Armonk, NY, USA, 2015.

54. Bujang, M.; Sa'at, N.; Sidik, T.; Joo, L. Sample Size Guidelines for Logistic Regression from Observational Studies with Large Population: Emphasis on the Accuracy Between Statistics and Parameters Based on Real Life Clinical Data. Malays. J. Med. Sci. 2018, 25, 122-130. [CrossRef] [PubMed]

55. Peduzzi, P.; Concato, J.; Kemper, E.; Holford, T.; Feinstein, A. A simulation study of the number of events per variable in logistic regression analysis. J. Clin. Epidemiol. 1996, 49, 1373-1379. [CrossRef]

56. Harrell, F.; Lee, K.; Mark, D. Multivariable prognostic models: Issues in developing models, evaluating assumptions and adequacy, and measuring and reducing errors. Stat. Med. 1996, 15, 361-387. [CrossRef]

57. Fox, J. Bootstrapping Regression Models Appendix to An R and S-PLUS Companion to Applied Regression. 2002. Available online: https:/ / statweb.stanford.edu/ \{\}tibs/sta305files/FoxOnBootingRegInR.pdf (accessed on 5 February 2021). 